\title{
A study to establish normal reference values of urine flow parameters in healthy South African females
}

\author{
Z Abdool, ${ }^{1}$ MB ChB, FCOG (SA), MMed (O\&G), MPhil, PhD; N E Manana, ${ }^{1}$ MB ChB, FCOG (SA); P Becker, ${ }^{2}$ MSc, PhD
}

${ }^{1}$ Department of Urogynaecology, University of Pretoria, Steve Biko Academic Hospital, Pretoria, South Africa

${ }^{2}$ Faculty of Health Sciences, University of Pretoria, South Africa

Corresponding author: Z Abdool (zeelha.abdool@up.ac.za)

Background. Several studies have demonstrated the negative impact of lower urinary tract symptoms on health-related quality of life domains. Uroflowmetry is a simple screening test performed after taking a detailed history and examination of the patient. However, unlike men, there are no universally accepted and population-specific uroflow nomograms available for women.

Objective. To determine the normal reference values for various uroflow parameters in a healthy female South African population and to determine ethnic variations in measured parameters.

Methods. This was a cross-sectional study done at a tertiary hospital in Pretoria. Recruited females included healthy staff members, students, patients, and their relatives who attended the gynaecology outpatient department. Quantile regression was used to formulate uroflow centiles using average and maximum urine flow rate over voided volume.

Results. We recruited 336 females out of 353 volunteers ( $n=306$ for study group and $n=30$ for control group). The mean (standard deviation (SD)) age was 35.15 (10.24) years, voided volume 179.71 (136.10) $\mathrm{mL}$, voiding time (26.13 (19.48) s), time to maximum flow rate (Qmax) (5.85 (4.19) s), Qmax (20.01 (9.67) mL/s) and average flow rate (Qave) (10.16 (5.40) mL/s). Confidence limit flow-volume nomograms were developed, and these were validated against asymptomatic women $(n=30)$. Black females $(n=255)$ had statistically significantly higher average urine flow rate $(p=0.023)$ than white females $(n=55)$.

Conclusion. The generated nomograms in healthy women add to current scientific literature on this topic. Potential ethnic variation in uroflowmetry parameters needs further exploration.

Keywords. uroflowmetry; nomograms; lower urinary tract symptoms.

S Afr J Obstet Gynaecol 2020;26(3):105-109. https://doi/org/10.7196/SAJOG.2020.v26i3.2014

Patients frequently present with a constellation of nonspecific lower urinary tract symptoms (LUTS) echoing the often quoted statement that 'the bladder is an unreliable witness...it has a limited means of expressing its own pathology. ${ }^{[1]}$ Historically, the term LUTS is divided into three symptom-based categories, namely: storage, voiding and post-micturition. In women, this 'umbrella' term has been mainly associated with overactive bladder, indicative of storage symptoms, while voiding LUTS may also be present simultaneously. ${ }^{[2,3]}$ As clinical symptoms and signs of LUTS may be complex, nonspecific and overlapping, clinicians suggest additional specialised investigations such as urodynamic studies (UDS). ${ }^{[4]}$

The term 'urodynamics' was first coined by David M. Davis in 1954, followed by the International Continence Society (ICS) who then first defined the term 'urodynamic studies' in 1988. . $^{[5,6]}$ Significant academic interest and contributions from various fields led to this study being recommended by several international societies to assess function of the lower urinary tract. ${ }^{[7,8]}$

Uroflowmetry is one subset of a series of UDS that is performed to assess global voiding function. It is a relatively simple investigation, noninvasive, easy to do and financially feasible. According to the Good Urodynamic Practice 2002 guideline (GUP2002), uroflowmetry is defined as a test that produces the 'flow rate of the external urinary stream as volume per unit time in millilitres per second $(\mathrm{mL} / \mathrm{s})^{\cdot}{ }^{[}{ }^{[7]}$ Unlike men, there is no universally accepted uroflow nomogram available for women. Differing voiding physiology between females and males (i.e. shorter urethra and lack of resistance in women) necessitate female-specific nomograms. ${ }^{[9,10]}$ Universal application of Liverpool nomograms may be inappropriate for females due to the lack of population-specific comparisons. In addition, it is plausible that voiding parameters are subject to ethnic variations as it has been previously shown that there are ethnic differences in both urethral and pelvic floor morphology. ${ }^{[1,12]}$

The aim of the present study was to establish normal uroflow reference values of urinary flow parameters for a healthy South African (SA) female population, aged 18 - 60 years. In addition, we constructed nomograms to evaluate the association between the changes in flow rates at different voided volumes (VVs). We also examined whether uroflow parameters were influenced by parity, age, body mass index (BMI) and ethnicity.

\section{Methods}

This prospective cross-sectional study was conducted at a tertiary urogynaecological referral hospital (Steve Biko Academic Hospital) in Pretoria, SA, from September 2017 to November 2018. Recruited females included healthy staff members, nursing students and patients from the gynaecology outpatient department. Ethical approval was obtained from the University of Pretoria Ethics Committee (ref. no. 273/2017). 
Patients presenting to the gynaecology outpatient department between the ages of 18 - 60 years were informed about the study and asked if they were interested to participate. These included women consulting for low-risk gynaecological issues not related to bladder conditions. Females were excluded if they were pregnant, HIVpositive, had any neurological disease, pelvic organ prolapse, pelvic masses, and lower urinary tract symptoms, and if they were receiving treatment for a lower urinary tract condition or had any previous pelvic surgery/pelvic radiation.

Students from the local medical school and nursing college were also informed about the study through pamphlets and asked to report to the urogynaecology clinic if interested. Like other uroflow nomogram studies, an additional group of healthy patients' relatives was also selected for validation of the nomograms. The purpose of including healthy females was to determine whether the measured parameters were comparable to those measured from females recruited from the general gynaecology clinic.

All the eligible and consenting females were asked to report to the urogynaecology department with a comfortably full bladder for measurement of their urine flow. These were recorded in the privacy of a locked test room. The Solar Blue wireless uroflowmetry equipment (Medical Measurement Systems, The Netherlands) and the chair were positioned for the females' convenience and absolute privacy was maintained. The calibration of the flow measurement system was verified every 10 measurements as recommended by the ICS standards. ${ }^{[13]}$

Demographic information i.e. age, ethnicity, parity and body mass index (BMI), together with uroflowmetry parameters (i.e. voided volume, voiding time, time to maximum flow rate, calculated maximum (Qmax) and average flow rates (Qave)) were recorded. Uroflow values were coded for each subject and were digitally and physically stored for future analysis. All participants' information was anonymised, and data analysis was performed using the Stata software, version 15.1 (StataCorp., USA). Continuous variables are presented as mean (standard deviation (SD)) and categorical variables such as parity and BMI as percentages. A $p$-value $<0.05$ was statistically significant. Quantile regression was employed to estimate the centile curves in the nomograms. Multivariate analysis was used to study the effect of age, parity and BMI on corrected Qave.

\section{Results}

A total of 353 females were recruited between September 2017 and November 2018. Some females $(n=47)$ were excluded owing to a low voided volume $(<50 \mathrm{~mL})$. Demographic characteristics and uroflowmetry parameters of 336 eligible females were analysed. The study group constituted of 306 females. Most of the females were black $(n=255 ; 83.3 \%)$ and the rest were white $(n=51 ; 16.7 \%)$. The healthy control group $(n=30)$ consisted of $86.6 \%(n=26)$ black females and $13.3 \%(n=4)$ white females.

The summary statistics of the study v. the control group are presented as a mean (SD) in Table 1. Parity was divided into 3 groups: group 1 ( $n=153 ; 45.5 \%)$ were nulliparous; group $2(n=123 ; 36.6 \%)$ were para $1-2$; and group $3(n=60 ; 17.9 \%)$ were parity $\geq 3$. Females exhibited similarities in BMI with $34 \%(n=114)$ being normal, $31.8 \%(n=107)$ were overweight and $34.2 \%(n=115)$ were obese. None of the females was found to be underweight. Overall, the two groups did not differ by age, parity, BMI and measured uroflowmetry parameters except for voided volume $(p=0.020)$. This was controlled for in the analysis of ethnic variations.

\section{Ethnic variation analysis: Black v. white females}

Table 2 illustrates the analysis of both the demographic and measured uroflowmetry parameters. Black women had a greater parity $(p=0.035)$ while age and BMI were similar. This was controlled for in the analysis of the uroflowmetry parameters. There was also a statistically significant difference $(p=0.023)$ in the mean (SD) Qave between the Black (10.55 (5.39)) and white females $(8.96$ (5.16)), while there was no statistically significant difference in Qmax values between the two groups.

We analysed the influence of parity, age and BMI on Qave and found that there was no significant difference between the parity categories and Qave. Age did not significantly influence Qave $(p=0.147)$ and Qave was not significantly different in the different BMI categories ( $p=0.668)$.

To construct the nomograms, a goodness of fit test revealed that a logarithmic function bests described the relationship between Qmax/Qave and voided volume. The constructed nomograms (using quantile regression) are represented in the form of confidence interval limits (5th to 95th centile) for Qave and Qmax (Figs 1 and 2). The centiles indicated that Qave and Qmax are directly proportional to VV with a curve that gradually declines in the plateau phase over VV of $400 \mathrm{~mL}$.

\section{Discussion}

Uroflowmetry is regarded as a first-line screening investigation for most women with LUTS. The clinical value of these constructed nomograms enable clinicians to determine normal uroflow reference ranges in females presenting with LUTS in our local population. Recently, there has been a renewed interest on developing population and/or ethnicity-specific flow-volume nomograms. It is apparent

Table 1. Comparison of mean (SD) of control group v. the study group

\begin{tabular}{llll}
\hline Parameter & $\begin{array}{l}\text { Control group }(\boldsymbol{n}=\mathbf{3 0}), \\
\text { mean }(\mathrm{SD})^{*}\end{array}$ & $\begin{array}{l}\text { Study group }(\boldsymbol{n}=\mathbf{3 0 6}), \\
\text { mean }(\mathrm{SD})^{*}\end{array}$ & $\boldsymbol{p}$-value \\
\hline Age, years & $33.73(10.23)$ & $35.15(10.24)$ & 0.765 \\
Parity category, \% & & & \\
$\quad$ Nulliparous & 50 & 45.1 & 0.820 \\
$\quad$ Para 1 - & 36.7 & 36.6 & \\
$\quad$ PPara 3 & 13.3 & 18.3 & \\
BMI category, \% & & & 0.341 \\
$\quad$ Normal & 40 & 33.3 & \\
$\quad$ Overweight & 20 & 33.0 & 0.020 \\
$\quad$ Obese & 40 & 33.67 & 0.071 \\
Voided volume (mL) & $233.33(139.28)$ & $179.71(136.10)$ & 0.833 \\
Voiding time (s) & $31.63(20.78)$ & $26.13(19.48)$ & 0.064 \\
Time to maximum flow (s) & $5.1(2.50)$ & $5.85(4.19)$ & 0.087 \\
Qmax (mL/s) & $22.83(10.01)$ & $20.01(9.67)$ & \\
Qave (mL/s) & $11.56(5.12)$ & $10.16(5.4)$ & \\
SD = standard deviation; BMI = body mass index; Qmax = maximum flow rate; Qave = average flow rate. & \\
${ }^{*}$ Unless otherwise specified. &
\end{tabular}


that most studies included women of white origin from Western countries and East Indian origin. ${ }^{[10,14-17]}$ This is the first study to examine flow parameters in Black and white SA women.

While it is unclear whether there are major ethnic differences, consensus and standardisation of the measured parameters will aid clinicians to interpret findings more accurately. Table 3 compares the mean (SD or range) of three different ethnic groups and results from a pooled analysis composed of heterogeneous ethnic groups (mainly white). Overall, the findings for age, voiding time and maximum flow rate are similar. Differences in parameters such as time to maximum flow may be explained by unique functional and morphological differences of the pelvic floor (i.e. bladder neck, urethra and pelvic floor strength). ${ }^{[18-20]}$

In 1975, Dr. J Knobel ${ }^{[18]}$ studied ethnic differences in urethral morphology using a Foley catheter in SA women.
He found that black nulliparous and parous women had longer urethral lengths (average age was 25.17 years; urethral length $4.8 \mathrm{~cm}$ ) than Indian women (average age 27.4 years; urethral length $3.9 \mathrm{~cm}$ ) as well as greater contractile strength of the pelvic floor as measured by a Kegel perineometer. ${ }^{[18]}$ Howard et al. ${ }^{[19]}$ compared urethral structure and function and urethral support in 18 black American and 17 white nulliparous asymptomatic women. Greater average urethral closure pressure at maximal pelvic floor contraction and greater maximum urethral closure pressure at rest were notable functional differences among black American women. Morphological differences included larger urethral volumes (4 $818 \mathrm{~mm}^{3}$ v. $3977 \mathrm{~mm}^{3}$; $p=0.06$ ), greater ultrasonographically measured vesical neck mobility $(p=0.08)$ at maximum Valsalva effort. ${ }^{[19]}$ This concurs with

Table 2. Comparison of mean (SD) values between black $(n=281)$ and white $(n=55)$ participants

\begin{tabular}{llll}
\hline Parameter & $\begin{array}{l}\text { Black, } \\
\text { mean }(\mathrm{SD})^{*}\end{array}$ & $\begin{array}{l}\text { White, } \\
\text { mean }(\mathrm{SD})^{*}\end{array}$ & $\boldsymbol{p}$-value \\
\hline Age, years & $35.37( \pm 10.11)$ & $33.25( \pm 10.77)$ & 0.080 \\
Parity category, \% & & 0.035 \\
$\quad$ Nulliparous & 42.3 & 61.8 & \\
$\quad$ Para 1 - & 38.7 & 25.5 & \\
$\quad$ Para 3 & 19.0 & 12.7 & \\
BMI category, \% & & & \\
$\quad$ Normal & 35.2 & 27.3 & \\
$\quad$ Overweight & 31.7 & 32.7 & 0.077 \\
$\quad$ Obese & 33.1 & 40.0 & 0.929 \\
Voided volume (mL) & $189.19(139.63)$ & $160.49(121.20)$ & 0.097 \\
Voiding time (sec) & $25.92(17.76)$ & $30.18(27.19)$ & 0.080 \\
Time to maximum flow (sec) & $5.59(3.47)$ & $6.76(6.27)$ & 0.023 \\
Qmax (mL/sec) & $20.59(9.77)$ & $18.58(9.13)$ & \\
Qave (mL/sec) & $10.55(5.39)$ & $8.96(5.16)$ & \\
SD = standard deviation; BMI = body mass index; Qmax = maximum flow rate; Qave = average flow rate. &
\end{tabular}

previously published data from our unit demonstrating greater bladder neck decent in SA black compared with white and South Asian women. ${ }^{[20]}$

Development of flow-volume nomograms is essential to further understand the relationship between volumes and voiding parameters. Our nomograms were constructed using Qmax and Qave covering a wide range of VVs. We found a strong correlation between Qmax and Qave with VV, concurring with the findings reported by Barapatre et al. ${ }^{[15]}$ Using the same equipment as in our study, the author constructed flow-volume and flow-age nomograms using a cohort of 382 healthy women. This group found a significant positive correlation between Qmax/Qave and VV. This was further confirmed in a systematic review by Sorel et al., ${ }^{[21]}$ who found that six studies also found a positive relationship between Qmax and VV. Kumar et al. ${ }^{[16]}$ reported that after a VV of $700 \mathrm{~mL}$, there is a plateau followed by a decline in Qmax while Pernkopt et al. ${ }^{[22]}$ found a positive correlation until VV of $350 \mathrm{~mL}$ in adolescent males. ${ }^{[16,22]}$ The centiles generated in the present study illustrated a proportional relationship of Qmax and Qave with VV until $400 \mathrm{~mL}$, followed by a plateau phase.

The lack of age-flow rate corrected nomograms is attributed to a lack of consensus on this relationship. We did not find any correlation between Qave with age, parity and BMI. Fantl et al. ${ }^{[23]}$ studied flow time, VV, peak flow rate and time to peak flow rate in 60 women $(n=20$, postmenopausal) and found that the measured parameters were not influenced by age, parity, weight or menstrual cycle phase. The systematic review by Sorel et al. ${ }^{[21]}$ concludes that 'there was no clear

Table 3. Comparison of measured uroflowmetry parameters

\begin{tabular}{|c|c|c|c|c|}
\hline Parameters & $\begin{array}{l}\text { Abdool } \text { et al. } \\
(n=306), \text { mean }(\mathrm{SD})^{*}\end{array}$ & $\begin{array}{l}\text { Haylen } \text { et al }{ }^{[28]}(n=249) \text {, } \\
\text { mean }(\mathrm{SD})^{*}\end{array}$ & $\begin{array}{l}\text { Barapatre } \text { et } a l .{ }^{[15]}(n=308) \text {, } \\
\text { mean }(\mathrm{SD})^{*}\end{array}$ & $\begin{array}{l}\text { Sorel } \text { et al. },^{[21]} \\
\text { mean }(\mathrm{SD})^{*}\end{array}$ \\
\hline Demographic location & South Africa & Australia & India & NA \\
\hline Ethnicity & Black and white & white & Indian & NA \\
\hline Age, years & $35.15(10.24)$ & $37.3(13.4)$ & $33(8.63)$ & $37.1^{\dagger}$ \\
\hline Voided volume (mL), median (IQR) & $179.71(136.10)$ & $171(15-600)$ & $289.79(166.52)$ & $338(161)^{\dagger}$ \\
\hline Voiding time (s) & $26.13(19.48)$ & NA & $23.5(12.52)$ & $29(17)^{\dagger}$ \\
\hline Qmax $(\mathrm{mL} / \mathrm{s})$ & $20.01(9.67)$ & $22.4(10)$ & $23.06(9.40)$ & $23.5(10)^{\dagger}$ \\
\hline Qave $(\mathrm{mL} / \mathrm{s})$ & $10.16(5.4)$ & 12.58 & $13.08(6)$ & $13(6)^{\dagger}$ \\
\hline Post-void residual (mL) & NA & NA & $2.92(3.69)$ & $15.5(25)^{\dagger}$ \\
\hline
\end{tabular}




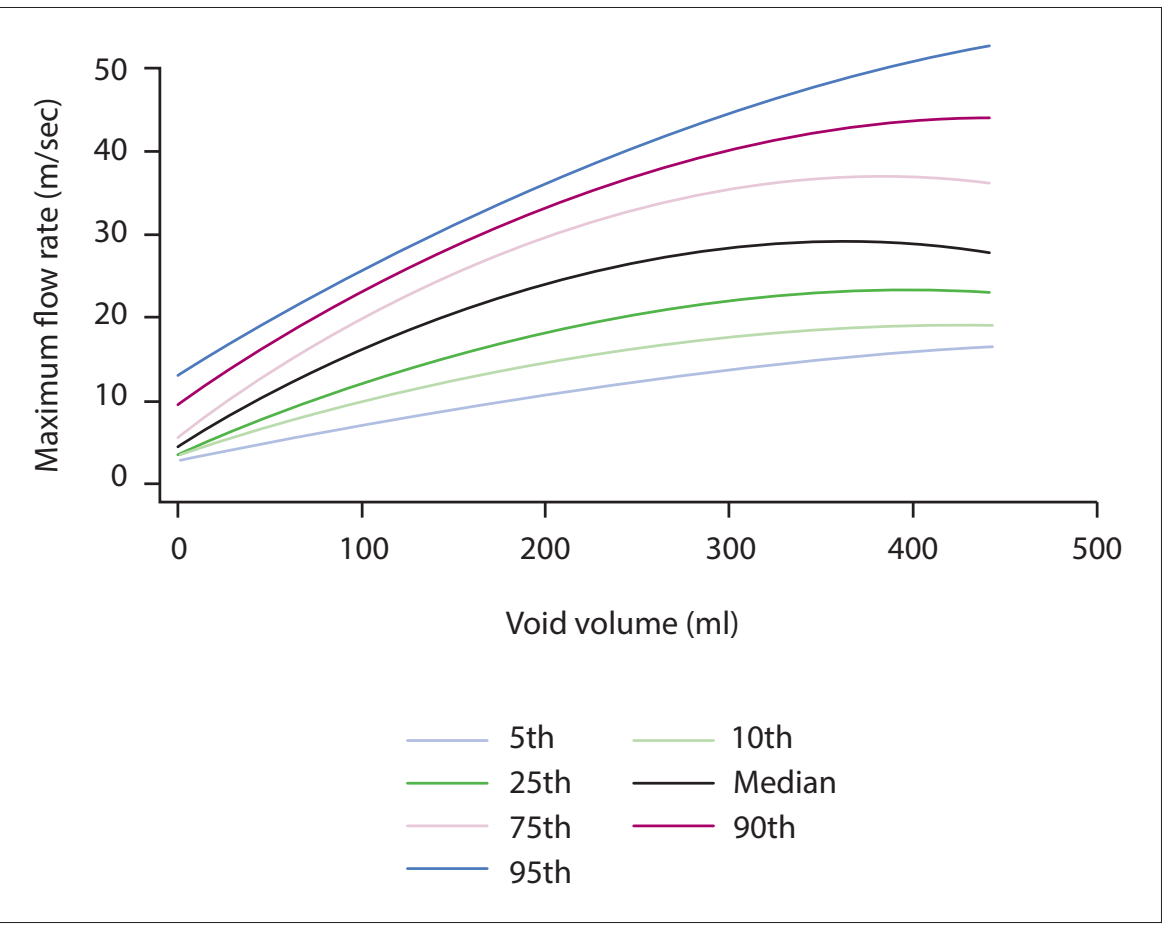

Fig. 1. Peak flow rate and voided volume nomogram.

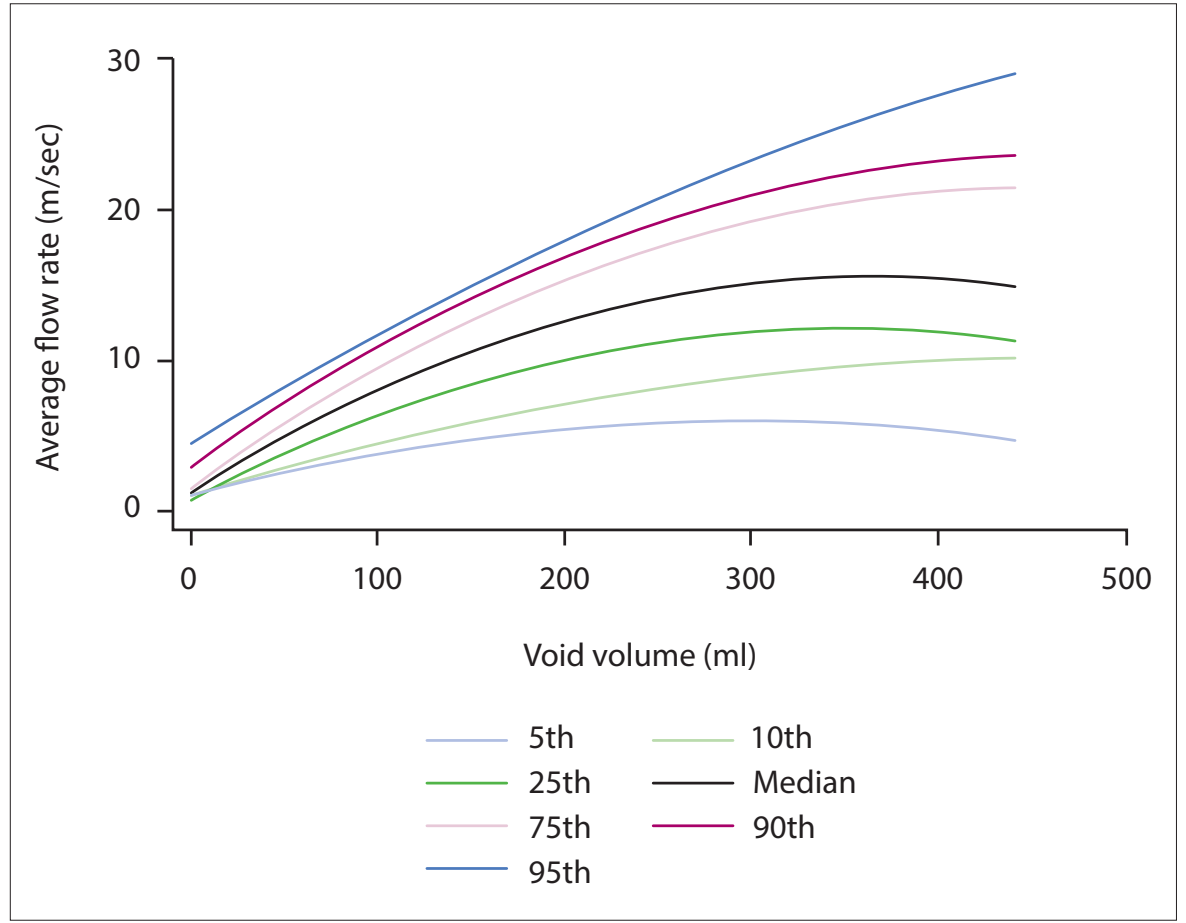

Fig. 2. Average flow rate and voided volume nomogram.

relationship between Qmax and age, and no correlation between parity and Qmax. ${ }^{\text {'21] }}$ Barapatre et al. ${ }^{[15]}$ also constructed centile nomograms for 382 healthy Indian women and found a negative association between Qmax/Qave and age. Similar findings were noted by Kumar et al. ${ }^{[16]}$ in a study that included 202 premenopausal and 97 postmenopausal women. ${ }^{[16]}$

In the present study, we decided to perform only one uroflow per participant as

\section{Conclusion}

This is the first study determining reference values of uroflow parameters in a healthy SA population with ethnic comparative data. We found that Qmax and Qave have a strong correlation with VV and Qave was not influenced by age, parity and BMI. In addition, Qave was significantly higher in black females compared with caucasian females $(p<0.023)$. This unique finding perhaps needs further scientific evaluation. Uroflowmetry centile nomograms were generated based on the correlations between VV and flow rates. The ability of uroflowmetry studies to provide potential limits of voiding normality is supported by its high degree of accuracy. The discriminatory ability (i.e. sensitivity and specificity, validation by comparison of parameters in women with LUTS) needs to be tested prospectively to determine the diagnostic ability of these constructed nomograms.

Declaration. This study was done in partial fulfilment of requirements for an MMed (O\&G) degree. Acknowledgements. None.

Author contributions. ZA conceptualised the study, analysed the data and wrote the manuscript. NM and PB analysed data and revised the manuscript. All authors approved the final manuscript for publication.

Funding. None.

Conflicts of interest. None.

1. Blaivas JG.The bladder is an unreliable witness. Neurourol Urodyn 1996;15(5):443-445. https://doi.org/10.1002 (SICI)1520-6777

2. Drake MJ, Abrams P. A commentary on expectations of healthcare professionals when applying the internationa continence society standards to basic assessment of lowe urinary tract function. Neurourol Urodyn 2018;37(S6):S7-S12 https://doi.org/10.1002/nau.23732

3. Choi YS, Kim JC, Lee KS, et al. Analysis of female voiding dysfunction: A prospective, multi-center study. Int Uro Nephrol 2013;45(4):989-994. https://doi.org/10.1007/s11255013-0475-2

4. Gordon D, Groutz A. Evaluation of female lower urinary tract symptoms: Overview and update. Curr Opin Obstet Gyneco 2001;13(5):521-527.

5. Davis DM. The hydrodynamics of the upper urinary tract (urodynamics). Ann Surg 1954;140(6):839.

6. Rosier PF, Schaefer W, Lose G, et al. International Continence Society good urodynamic practices and terms 2016: Urodynamics, uroflowmetry, cystometry, and pressure-flow study. Neurourol Urodyn 2017;36(5):1243-1260. https://doi org/10.1002/nau.23124

7. Abrams P, Cardozo L, Fall M, et al. The standardisation of terminology of lower urinary tract function: Report from the standardisation sub-committee of the International Continence Society. Neurourol Urodyn 2002;21:167-178. https://doi. org/10.1016/S0090-4295(02)02243-4 8. Van Doorn EvW, Anders K, Khullar V, et al. Standardisation of ambulatory urodynamic monitoring: Report of the standardisation sub-committee of the International Continence Society for Ambulatory Urodynamic Studies. Neurouro Urodyn 2000;19(2):113-125. https://doi.org/10.1002/(sici)1520-
6777(2000)19:2<113:aid-nau2

9. Haylen B, Parys B, Anyaegbunam WI, Ashby D, West C. Urine flow rates in male and female urodynamic patients compared with the Liverpool nomograms. Br J Urol 1990;65(5):483-487. https://doi.org/10.1111/j.1464-410x.1990.tb14791.

10. Haylen B, Ashby D, Sutherst JR, Frazer M, West C. Maximum and average urine flow rates in normal male and female population - the Liverpool nomograms. Br J Urol 1989;64(1):30-38. https:// doi.org/10.1111/j.1464-410x.1989.tb05518.x 


\section{RESEARCH}

11. Skinner D, Crichton D. Stress incontinence: A comparative racial study. Med Proc 1963:189-194

12. Derpapas A, Ahmed S, Vijaya G, et al. Racial differences in female urethral morphology and levator hiatal dimensions: An ultrasound study. Neurourol Urodyn 2012;31(4):502-507. https://doi. org $/ 10.1002 /$ nau. 21181

13. Gammie A, Clarkson B, Constantinou C, et al. International Continence Society guidelines on urodynamic equipment performance. Neurourol Urodyn 2014;33(4):370-379. https://dol. org $/ 10.1002 /$ nau. 22546

14. Rana Pratap Singh AJ. A study of normal female uroflowmetry for development of flow volume nomogram in an Indian population. Int J Contemp Med Res 2019;6(5):E1-E4. https://doi. org/10.21276/ijcmr.2019.6.5.34

15. Barapatre Y, Agarwal MM, Singh SK, et al. Uroflowmetry in healthy women: Development and validation of flow-volume and corrected flow-age nomograms. Neurourol Urodyn 2009;28(8):1003 1009. https://doi.org/10.1002/nau.20718

16. Kumar V, Dhabalia JV, Nelivigi GG, Punia MS, Suryavanshi M. Age, gender, and voided volume dependency of peak urinary flow rate and uroflowmetry nomogram in the Indian population. Ind Urol 2009;25(4):461-466. https://doi.org/10.4103/0970-1591.57912

17. Wyndaele JJ. Normality in urodynamics studied in healthy adults. J Urol 1999;161(3):899-902.

18. Knobel J. Stress incontinence in the black female. S Afr Med J 1975;49(12):430-432.

19. Howard D, Delancey JO, Tunn R, Ashton-Miller JA. Racial differences in the structure and function of the stress urinary continence mechanism. Obstet Gynecol 2000;95(5):713-717. https://doi. org/10.1016/s0029-7844(00)00786-9
20. Abdool Z, Dietz H, Lindeque B. Ethnic differences in the levator hiatus and pelvic organ descent A prospective observational study. Ultrasound Obstet Gynecol 2017;50(2):242-246. https://doi. org/10.1002/uog. 17297

21. Sorel MR, Reitsma HJ, Rosier PF, Bosch RJ, de Kort LM. Uroflowmetry in healthy women: A systematic review. Neurourol Urodyn 2017;36(4):953-959. https://doi.org/10.1002/nau.23051

22. Pernkopf D, Plas E, Lang T, et al. Uroflow nomogram for male adolescents. J Urol 2005;174(4 Part 1):1436-1439. https://doi.org/10.1097/01.ju.0000173694.86127.ae

23. Fantl JA, Smith PJ, Schneider V, Hurt WG, Dunn LJ. Fluid weight uroflowmetry in women. Am J Obstet Gynecol 1983;145(8):1017-1023. https://doi.org/10.1016/0002-9378(83)90860-8

24. Haylen BT, Yang V, Logan V. Uroflowmetry: Its current clinical utility for women. Int Urogynecol J 2008;19(7):899-903. https://doi.org/10.1007/s00192-008-0597-8

25. Devreese AM, Nuyens G, Staes F, Vereecken R, De Weerdt W, Stappaerts K. Do posture and straining influence urinary-flow parameters in normal women? Neurourol Urodyn 2000;19(1):3-8. straining influence urinary-flow parameters in
https://doi.org/10.1002/(SICI) $1520-6777$ (2000)

26. Sørensen S, Jønler M, Knudsen U, Djurhuus J. The influence of a urethral catheter and age on recorded urinary flow rates in healthy women. Scand J Urol Nephrol 1989;23(4):261-266. https:// doi.org/10.3109/00365598909180335

Accepted 7 June 2021. 